Portland State University

PDXScholar

Mechanical and Materials Engineering Faculty

Publications and Presentations

Mechanical and Materials Engineering

$12-12-2018$

\title{
Assessment of Cooling and Heat Transfer Properties of Quenchants with MATLAB
}

\author{
Lemmy Meekisho \\ Portland State University, lemmy@pdx.edu \\ Rosa L. Simencio Otero \\ Universidade de São Paulo \\ Jônatas M. Viscaino \\ Universidade de São Paulo \\ D. Scott MacKenzie \\ Houghton International, Inc. \\ George Totten \\ Portland State University, getotten@gmail.com
}

See next page for additional authors

Follow this and additional works at: https://pdxscholar.library.pdx.edu/mengin_fac

Part of the Mechanical Engineering Commons

Let us know how access to this document benefits you.

\section{Citation Details}

Meekisho, L., Simencio Otero, R. L., Viscaino, J. M., Scott MacKenzie, D., Totten, G. E., and Canale, L. C. F., "Assessment of Cooling and Heat Transfer Properties of Quenchants with MATLAB," Materials Performance and Characterization.

This Article is brought to you for free and open access. It has been accepted for inclusion in Mechanical and Materials Engineering Faculty Publications and Presentations by an authorized administrator of PDXScholar. Please contact us if we can make this document more accessible: pdxscholar@pdx.edu. 


\section{Authors}

Lemmy Meekisho, Rosa L. Simencio Otero, Jônatas M. Viscaino, D. Scott MacKenzie, George Totten, and Lauralice C.F. Canale 
Manuscript received March 8 , 2018; accepted for publication August 3, 2018; published online December 12, 2018.

1 Portland State University, Department of Mechanical and Materials Engineering, PO Box 751, Portland, OR, USA, (D) https:// orcid.org/0000-0002-7313-1437 (G.E.T.)

2 Department of Materials Engineering, São Carlos School of Engineering, University of São Paulo, Av. João Dagnone, 110, São Carlos, SP, 13563-120, Brazil, (Corresponding author), e-mail: rosa_simencio@yahoo. com.br, (10) https://orcid.org/ 0000-0002-1974-6406

${ }^{3}$ Department of Materials Engineering, São Carlos School of Engineering, University of São Paulo, Av. João Dagnone, 110, São Carlos, SP, 13563-120, Brazil, (1) https://orcid.org/0000-00020193-1902 (L.C.F.C.)

${ }^{4}$ Houghton International, Inc., 930 Madison Ave., Valley Forge, PA 19482, USA, (D) https://orcid. org/0000-0001-7107-9930
Lemmy Meekisho, ${ }^{1}$ Rosa L. Simencio Otero, ${ }^{2}$ Jônatas M. Viscaino, ${ }^{3}$ D. Scott MacKenzie, ${ }^{4}$ George E. Totten, ${ }^{1}$ and Lauralice C. F. Canale ${ }^{3}$

\section{Assessment of Cooling and Heat Transfer Properties of Quenchants with MATLAB}

\section{Reference}

Meekisho, L., Simencio Otero, R. L., Viscaino, J. M., Scott MacKenzie, D., Totten, G. E., and Canale, L. C. F., "Assessment of Cooling and Heat Transfer Properties of Quenchants with MATLAB," Materials Performance and Characterization https:// doi.org/10.1520/MPC20180046. ISSN 2379-1365

\section{ABSTRACT}

There is ongoing interest for evaluating the potential of renewable base stocks, such as vegetable oils, to replace petroleum oils as metal quenchants. Perhaps the most critical part of this process is characterizing and comparing the cooling and heat transfer performance of potential quenchant candidates. In this work, cooling curves of two vegetable oils, palm oil and canola oil, were obtained along with a commercially available conventional and an accelerated petroleum quenchant using the so-called Tensi multiple thermocouple probe, with emphasis on the center probe emulating a small probe concept. The lumped-parameter approach was implemented in the MATLAB environment (Mathworks Inc., Natick, MA). Experimental quenching data along with temperature-dependent thermal properties for the Inconel probe material were used to quantify the cooling characteristics and heat transfer properties of two typical vegetable and petroleum oil quenchants. The results obtained exhibited a fundamental difference in the cooling characteristics between the vegetable oils and also between both vegetable oils and the petroleum oil quenchants evaluated. The focus of this article will be on the development of the computational codes and the use of MATLAB to perform these analyses.

\section{Keywords}

quenchant, cooling curve, lumped-parameter, MATLAB, heat transfer coefficient 


\section{Introduction}

Vegetable oils and animal oils have been used as quenchants for metals for thousands of years. Historically, very little is known about quenching selection and practice prior to approximately $1500 \mathrm{AD}$ [1]. Although cold water was a common quenchant, it may lead to cracking problems with brittle steels. However, it was reported at the time that these problems could be solved by mixing water and various animal and plant materials to make an "oily" or "pulpy" quenching bath. Other quench hardening processes that were reported included the following: scythes in suet, files in linseed oil and goat's blood, quarry hammers in the juice of crushed caterpillars, and the edges of steel cutting tools in a composition containing one part each of radishes, horseradish, earthworms or larvae, and billy goat's blood when the goat is in a "rut" (a quenching recipe reported to originate from the time of Pliny the Younger: 61- ca. 112 AD [2]). MacKenzie has recently noted that the actual use of many of these quenchants, other than water, was unlikely in view of their relative inability to harden carbon steel [3].

Perhaps the first to publish rigorous comparative quenchant analyses of a reasonably broad series of vegetable oils was Tagaya and Tamura [4]. Their work involves determination of the structural composition of a series of vegetable oils for correlation with cooling curve properties. This comparison included typical petroleum oils in use at the time. The cooling curve comparison indicated that vegetable oils as a group did not exhibit any significant film boiling behavior when compared to petroleum oil quenchants.

Recently, Carvalho et al. [5,6]; Belinato, Canale, and Totten [7]; and others have similarly examined the quenching behavior of vegetable oils using cooling time and rates. These cooling curve data parameters were also compared to typical petroleum oil quenchants, and the results similarly indicated very short, if observable, film-boiling regions for vegetable oils in general when compared to petroleum oil quenchants. Furthermore, vegetable oils also generally exhibited higher cooling rates at $\leq 300^{\circ} \mathrm{C}$. However, heat transfer data were not calculated in these studies.

More recently, Otero et al. [8] and Kobasko et al. [9] have reported heat transfer coefficient (HTC) values for various vegetable oils that were obtained using a "simplified" computational method $[9,10]$. Although relatively easy to perform, this method does not readily produce vitally important continuous heat transfer profiles for a quenching medium throughout the cooling process. Such data are much more readily obtained by using an inverse method, such as the finite element methods (FEMs) utilized by many workers and recent studies involving vegetable oils reported by Kobasko et al. [9]; Carvalho et al. [11]; Jagannesh and Prabhu [12]; Ramesh and Prabhu [13]; and others who have utilized FEMs, to solve the heat transfer problem.

For much of the more recently reported work, a 12.5-mm-diameter, 60-mm-long INCONEL 600 cylindrical probe with a Type K thermocouple (TC) inserted into the geometric center was used as the probe for temperature-time data acquisition of the quenching process. The use of this single TC probe is specified in the following cooling curve analysis standards: ASTM D6200, Standard Test Method for Determination of Cooling Characteristics of Quench Oils by Cooling Curve Analysis [14]; ASTM D6482, Standard Test Method for Determination of Cooling Characteristics of Aqueous Polymer Quenchants by Cooling Curve Analysis with Agitation (Tensi Method) [15]; and ASTM D6549, Standard Test Method for Determination of Cooling Characteristics of Quenchants by Cooling Curve Analysis with Agitation (Drayton Unit) [16]. 
Liščić has utilized a larger cylindrical probe that is $50 \mathrm{~mm}$ in diameter and $200 \mathrm{~mm}$ long. The ratio between length and diameter is $4: 1$, which ensures that the heat dissipation through both ends of the probe is negligible so that in the cross-section at half-length where the TCs are positioned only radial heat flow exists, which is a prerequisite for a onedimensional heat-transfer calculation. The outer TC (the measured data of which are used as inputs for heat-transfer calculations) is placed at $1 \mathrm{~mm}$ below the surface to ensure minimum damping effect of transient surface temperatures. Also, the lagging effect (because of thermal diffusivity) is minimized because of the small distance to the surface. The response time (which depends on the outer diameter) of this 1-mm-diameter TC is relatively short and the data acquisition rate is 50 points/s. The remaining two TCs are placed at the center and mid-radius on the same plane as the near-surface TC. This probe is an essential component of the heat transfer "Gradient Method" utilized by Liščić to calculate the heat transfer properties of quenching media [17]. Recently, Liščićs Gradient Methodology was used to calculate heat transfer performance of canola oil and palm oil fluids containing antioxidants for comparison to a locally produced conventional petroleum oil quenchant [18].

MATLAB (MathWorks, Natick, MA) is a high-performance modeling program that integrates computation, visualization, and programming in an easy-to-use environment where problems and solutions are expressed in familiar mathematical notation used for technical computing; MATLAB is being used increasingly by scientists and engineers for research, development, and analysis [19,20]. Ackerman has reported that MATLAB has been used successfully for the following: computational mathematics, algorithm development, modeling, simulation, prototyping, data analysis, exploration, visualization, scientific and engineering graphics, and application development, including Graphical User Interface building [21]. The use of MATLAB (Matrix Laboratory) to calculate quenching performance, including heat transfer properties, from cooling temperaturetime curves is the focus of the work reported herein.

This article describes cooling curve data acquisition and comparison of aspurchased (no antioxidants) canola oil, palm oil, and two commercially available petroleum oil quenchants. These cooling curves were using the multiple TC Tensi probe, which is also described. However, these data were used because of their availability. For the work described in this particular study, only the time-temperature cooling data obtained for the centerline TC was used. The centerline temperature-time data files were then used for the computation of the heat transfer properties of these selected quenchant examples using MATLAB. The details of this computational work will be presented and described sequentially to enable the reader to readily perform similar computational work.

\section{Background of Quenchants Studied}

The two vegetable oils used for this work, canola oil and palm oil, were purchased at the local market in Sao Carlos, Brazil and were used in the as-purchased condition without the addition of antioxidants. Quenching performance of these oils was compared to two commercially available quenching oils: HoughtoQuench 100 (a conventional "slow" oil) and HoughtoQuench KM (HKM, an accelerated "fast" oil).

Cooling curves were obtained under unagitated conditions according to ASTM D620001 at bath temperatures of $40^{\circ} \mathrm{C}, 60^{\circ} \mathrm{C}, 80^{\circ} \mathrm{C}, 100^{\circ} \mathrm{C}$, and $120^{\circ} \mathrm{C}$ [14]. However, instead of the standard 12.5 -mm-diameter X $60-\mathrm{mm}$ cylindrical INCONEL 600 assembly specified in ASTM D6200, a multiple TC probe assembly (Tensi probe) shown in Fig. 1 was used. For 
FIG. 1 Schematic illustration of the Tensi probe assembly used for this work.

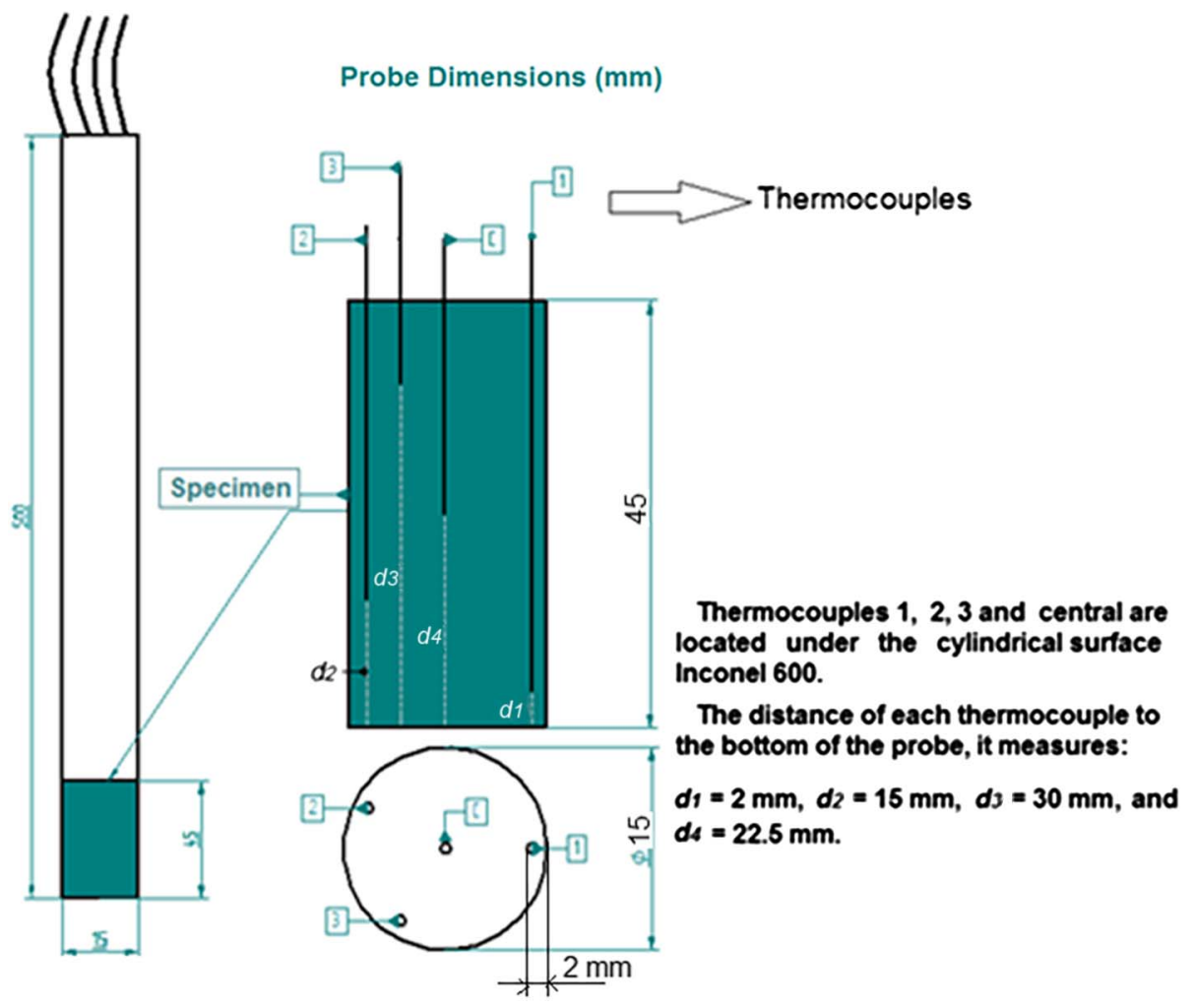

the MATLAB computations discussed here, data collected from the center TC were used to characterize the heat transfer characteristics of four quenchants. It is important to note that the time-temperature TC data obtained from the multiple-TC Tensi probe were used because they were available. For the work described herein, only the center TC time-temperature data were used because that was the only data necessary for the lumped-parameter computational approach utilized. For this work, the surface TC data were not used for the computations. The centerline TC data were used to better approximate the data attainable from the Inconel 600 single TC probe described in ASTM D6200, ASTM D6482, and ASTM D6549.

After heating the probe in a furnace to $850^{\circ} \mathrm{C}\left(1,562^{\circ} \mathrm{F}\right)$, it was then manually and rapidly immersed into $2,000 \mathrm{~mL}$ of the oil to be tested, which was contained in a tallform stainless steel beaker as required by the ASTM cooling curve standards. The probe cooling temperature and cooling times were obtained at a data acquisition rate of $8 \mathrm{~Hz}$, saved on disk storage, and used to establish a cooling temperature versus time curve. (This temperature-time data file was also used for the MATLAB computational work described in what follows.)

\section{MATLAB Computational Methodology}

MATLAB is a popular multi-paradigm commercial numerical computing and visualization environment developed and marketed by MathWorks, Inc. [22]. Furthermore, 
MATLAB is often preferred by engineering departments and is heavily used by some industries. In addition to these general advantages, MATLAB was used for this work because it is preferred for much of the computational development work at the author's university. However, the models developed here could be adapted for use with Excel and other computational programs, if desired.

MATLAB has hundreds of built in functions that can be used for technical computing, graphing, and animations including the following:

- linear algebra computations,

- data analysis,

- signal processing,

- optimization, and

- numerical solution of ordinary differential equations.

MATLAB may be used for a wide variety of tasks including matrix manipulations, data analysis, and plotting. While it is powerful and relatively easy to use as an interactive computing and plotting environment, its greatest potential is in the development of reusable scripts and $\mathrm{m}$-function files.

In this article, MATLAB was used to calculate quenching performance, including heat transfer properties (HTC), from experimentally measured temperature-time data for two vegetable oils and two commercially available conventional and accelerated petroleum quenchants. Excel might have been used for this work in view of its relative popularity and ease of use; however, it is much less powerful, especially for computations involving very large data sets.

\section{COMPUTATION OF HTCS FOR DIFFERENT QUENCHANTS}

In this article, it was assumed that the volume of the vegetable oil quenchants was large enough that its temperature was assumed to remain constant at room temperature. It was further assumed that the density, specific heat capacity, and thermal conductivity of the Inconel probe were constant throughout the quenching process.

Under equilibrium heat exchange conditions, when the probe is immersed into the quenchant, the heat lost by the probe through its surface by convection is equal to the decrease in the internal energy of the probe. This is effectively the lumped heat capacity approach for computing the HTC reported previously by Narazaki et al. [23] and Funatani, Narazaki, and Tanaka [24] previously and is the approach used for this work.

Specifically heat lost by the probe is computed as

$$
q_{A}=h A\left(T-T_{s}\right)
$$

where $h$ is the effective HTC $\left(\mathrm{W} / \mathrm{m}^{2} \mathrm{~K}\right), A$ is the surface area of probe, $T$ is the instantaneous temperature of probe, and $T_{s}$ is the temperature of the quenchant.

The decrease in internal energy of the probe is computed as

$$
q_{m}=-\rho V C_{p} \frac{\mathrm{d} T}{\mathrm{~d} t}
$$

where $\rho$ is the density of probe material, $V$ is the volume of the probe, $C_{p}$ is the specific heat capacity of probe material, and (J/kg.K), $\mathrm{d} T / \mathrm{d} t$ is the cooling rate of the probe.

Under equilibrium conditions and assuming minimum heat losses in the process, heat dissipated by probe equals heat absorbed by equivalent displaced volume of 
quenchant, i.e., $\mathrm{Eq} 1=\mathrm{Eq} 2$. Because the only unknown in the two equations is the effective HTC, the terms were rearranged into the following relationship (Eq 3) and coded in MATLAB to compute the respective HTCs at various time stations in the quenching process, as well as HTCs at different temperatures during the quenching process.

$$
h=-\rho C_{p} \frac{V}{A}\left(\frac{\mathrm{d} T / \mathrm{d} t}{T-T_{s}}\right)
$$

A MATLAB script similar to the one shown in Appendix A was used for reading EXCEL files in order to extract temperature-time data for analysis in this study. The script in reference, while more detailed, is shown here for brevity. All precautions were taken to ensure that the script could account for different time ranges for different thermocouples and different quenchants.

The following snippet of MATLAB code shows the steps for using temperature-time data for canola oil to compute the surface HTC using readings from the center probe only. Similar scripts were used for the other combinations of oil and TC. Thermal physical properties for the Inconel probe were obtained from Hosaeus et al. [25] and de Souza et al. [26].

$C p$ and density values implemented in Eq 3 were evaluated as a function of temperature, that is, respectively

$$
\begin{gathered}
C p=\mathrm{f}(T) \\
\rho=\mathrm{f}(T)
\end{gathered}
$$

Curve fitting procedures were implemented in MATLAB to compute an empirical polynomial function that fits best fit data from Ref. [25] to the following functions:

$$
\begin{gathered}
C p=-2.89845 * 10^{-7} T^{3}+3.45198 * 10^{-4} T^{2}+0.10302 T+450.75521 \\
\rho=-8.52341 * 10^{-5} T^{2}-3.06597 * 10^{-1} T+8,403.87017
\end{gathered}
$$

In the MATLAB codes for computing the HTC for the various quenchants according to Eq 3, values of specific heat and density for the Inconel probe were computed at the reference temperature in accordance with the fit polynomials in Eqs 6 and 7, respectively.

Biot number is the ratio of $L^{\star} h / k$, where $L$ is the ratio of the volume to surface area of the probe; $h$ and $k$ are the surface HTC and thermal conductivity of the probe. In this study, because of the relatively small TC size, it was practical to assume that the Biot number was small $[23,24]$. For larger TCs, or quenching conditions involving large Biot numbers, it would be prudent to explore the potential improvement of the lumped capacity method by using inverse heat transfer techniques.

In order to accommodate larger TCs, it will become necessary to include thermal conductivity effects across the section of the TC. Specifically, it will be necessary to treat thermal conductivity $(k)$ as a function of temperature:

$$
k=\mathrm{f}(T)
$$

Thermal conductivity values from Ref. [25] were also curve fit using MATLAB and the following empirical relationship: 


$$
k=3.14833 * 10^{-6} T^{2}+1.67717 * 10^{-2} T+12.50997
$$

The results extracted from the computations of HTCs are summarized in graphical summaries shown in the results section of this article. A subset of HTC versus temperature data for the four quenchants in this study are summarized in tables in the results section. The subset of data shown corresponds to the range for which the heat transfer behavior exhibit maxima.

\section{Results and Discussion}

The following is a summary of the results obtained from this study. Again, the focus was the data collected from the center TC of the multi-TC Tensi probe illustrated in Fig. 1. The centerline cooling time-temperature curves for palm oil, canola oil, and the HKM (fast) and H100 (conventional) petroleum quenchants are shown in Fig. 2. The corresponding cooling rate curves are shown Fig. 3.

Visual inspection of the cooling time-temperature curves and the cooling rate curves shown in Figs. 2 and 3, respectively, indicate that canola oil appears to cool with little or no film boiling behavior as indicated by extended slow cooling upon initial immersion. However, the cooling behavior for palm oil, also a triglyceride vegetable oil structure, does exhibit a significant film-boiling cooling region very similar to the HKM fast petroleum quenching oil. The conventional petroleum quenching oil, as expected, exhibited the longest duration of film boiling of the four quenchants evaluated.

It is important to note that petroleum oil quenchants are formulated with petroleum oil fractions that exhibit a range of boiling points and behaviors. Therefore, film boiling is expected for the petroleum oil-derived quenchants. However, vegetable oils do not boil. Instead, they oxidatively degrade above their smoke points. Because vegetable oils do not boil, such evidence of significant film boiling as exhibited by palm oil in this work is

FIG. 2

The centerline cooling curves for palm oil, canola oil, HKM, the fast (accelerated) pertroleum oil-based quenchant and $\mathrm{H} 100$, and the conventional petroleum oil-based quenchant. The curves were derived from the centerline TC shown for the Tensi probe illustrated in Fig. 1. The quenchants were unagitated and the bath temperature was $60^{\circ} \mathrm{C}$.

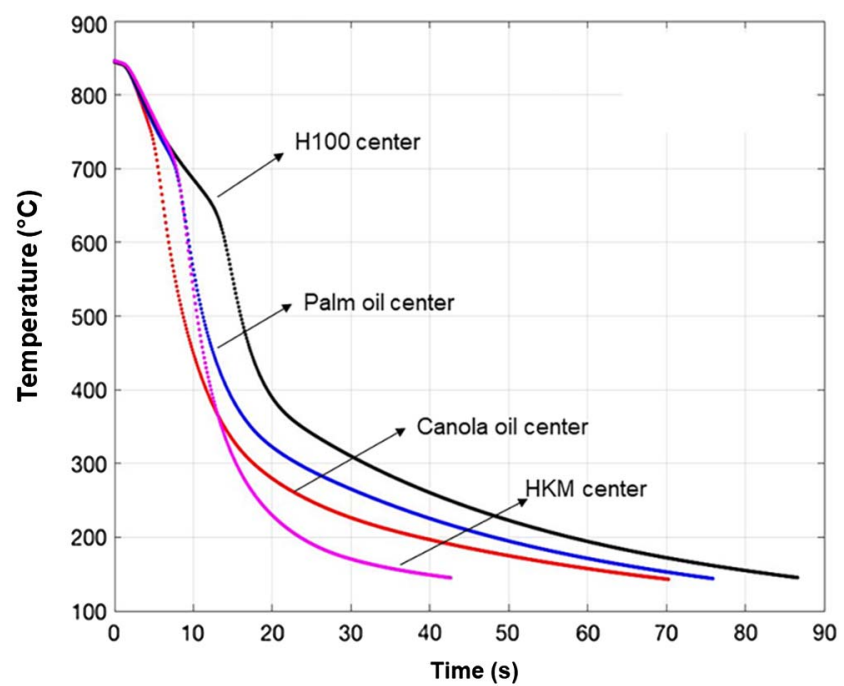




\section{FIG. 3}

The cooling rate curves for palm oil, canola oil, HKM, the fast (accelerated) pertroleum oilbased quenchant and $\mathrm{H} 100$, and the conventional petroleum oil-based quenchant. The curves were derived from the centerline TC shown for the Tensi probe illustrated in Fig. 1. The quenchants were unagitated and the bath temperature was $60^{\circ} \mathrm{C}$.



unexpected and most likely caused by the presence of volatile contaminants arising from the refining process used to produce this oil.

Surface HTCs were derived from the centerline cooling time-temperature data as discussed earlier in the MATLAB computational section of this article. The maximum HTC $\left(H T C_{\max }\right)$ coefficients obtained for each fluid tested were plotted as a function of time and are shown in Fig. 4. The cooling time for the maximum heat transfer to occur $\left(t_{\max }\right)$, the surface temperature at which the maximum heat transfer occurs $\left(T_{\max }\right)$, and the magnitude of $H T C_{\max }$ are summarized in Table 1.

Comparison of the HTC data shown in Fig. 4 and Table 1 shows that canola oil does exhibit a comparatively short film boiling behavior that transitions to nucleate boiling at a

\section{FIG. 4}

\section{Surface heat transfer}

coefficients as a function of temperature for canola oil, palm oil, HKM fast petroleum oil, and H100 conventional petroleum oil quenchant. These data were obtained at a bath temperature of $60^{\circ} \mathrm{C}$ and with no agitation.

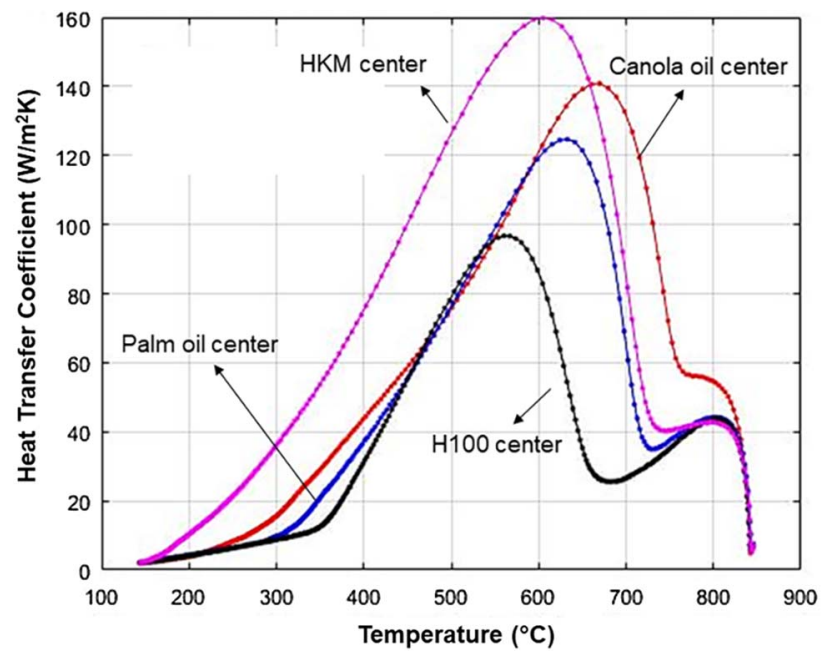


TABLE 1

Summary of the maximum heat transfer coefficients for the quenching fluids shown in Fig. 4.

\begin{tabular}{lccc}
\hline Quenchant & $t_{\max }, \mathrm{s}$ & $T_{\max },{ }^{\circ} \mathrm{C}$ & $H T C_{\max }, \mathrm{W} / \mathrm{m}^{2} \mathrm{~K}$ \\
\hline Canola oil & 5.875 & 669.8 & 140.9 \\
Palm oil & 8.875 & 632.8 & 124.7 \\
Houghtoquench HKM & 9.125 & 605 & 159.8 \\
Houghtoquench H100 & 14.75 & 560.3 & 96.7 \\
\hline
\end{tabular}

relatively high temperature. However, these data do confirm that palm oil does (unexpectedly, because vegetable oils do not boil) exhibit relatively long film boiling behavior that transitions to nucleate boiling at a much lower temperature than canola oil. Additionally, the $H T C_{\max }$ for canola oil occurs after a shorter time and with a larger magnitude than the path observed for palm oil.

The fast petroleum oil (HKM) exhibited a significantly shorter film boiling duration than the conventional petroleum oil quenchant (H100), and its $H T C_{\max }$ was the largest of all of the fluids studied. Interestingly, whereas the transition times were nearly the same for both palm oil and HKM, the HTC was much larger. The $H T C_{\max }$ was the lowest of the fluids studied.

The longer cooling times $\left(t_{\max }\right)$ and the lowest $H T C_{\max }$ are important measures that suggest that the conventional (slow) petroleum max provides the greatest stability to distortion and resistance to cracking of the fluids evaluated.

It is very important to put the results shown for vegetable oils in context because vegetable oils (if present in "pure" triglyceride oil) do not boil. The highest cooking (use) temperature for a vegetable oil is limited by the temperature at which the oil begins to smoke. Typical smoke points for common vegetable oils may vary from $121^{\circ} \mathrm{C}$ to $>232^{\circ} \mathrm{C}\left(250^{\circ} \mathrm{F}\right.$ to $\left.>450^{\circ} \mathrm{F}\right)$. The exact smoke points cannot be cited because of the normal compositional variation, refining method, seed variety, and even climate and weather during the plant's growing season. However, typical smoke points for common vegetable oils are as follows: safflower oil, $163^{\circ} \mathrm{C}-177^{\circ} \mathrm{C}\left(325^{\circ} \mathrm{F}-350^{\circ} \mathrm{F}\right)$; corn oil, $204^{\circ} \mathrm{C}-213^{\circ} \mathrm{C}$ $\left(400^{\circ} \mathrm{F}-415^{\circ} \mathrm{F}\right)$; peanut oil, $216^{\circ} \mathrm{C}-221^{\circ} \mathrm{C}\left(420^{\circ} \mathrm{F}-430^{\circ} \mathrm{F}\right)$; cottonseed oil, $218^{\circ} \mathrm{C}-227^{\circ} \mathrm{C}$ $\left(425^{\circ} \mathrm{F}-440^{\circ} \mathrm{F}\right)$; canola oil, $224^{\circ} \mathrm{C}-229^{\circ} \mathrm{C}\left(435^{\circ} \mathrm{F}-445^{\circ} \mathrm{F}\right)$; and sunflower and soybean oils, $227^{\circ} \mathrm{C}-232^{\circ} \mathrm{C}\left(440^{\circ} \mathrm{F}-450^{\circ} \mathrm{F}\right)$ [27]. At atmospheric pressures and temperatures greater than the smoke point, vegetable oils degrade; they do not boil.

However, commercially available vegetable oils are not pure single component fluids, but they contain a range of different triglyceride structures, which are dependent on the particular seed oil. Normally, they are refined by a variety of possible methods, but even after refining, they may still potentially contain small quantities of by-products. (Typical refining and purification practice and composition of commercial palm oil is described in Ref. [28].)

In addition to monoglyceride and diglyceride structures, vegetable oils may also contain free fatty acids, tocopherols, sterols, phenolic compounds, phospholipids, and other variants as well as low concentrations of water $[29,30]$. Some of these compounds contribute to potential volatility, which may be observed as film boiling during immersion quenching by hot steel. Unless the as-purchased vegetable oils are further purified, they all contain a number of these potential by-products at varying concentrations depending on the refining process and its effectiveness. All of the vegetable oils reported here were used in the as-purchased condition. However, based on the cooling curves shown here 
where canola oil exhibits a comparatively very short film boiling behavior compared to palm oil, it is concluded that the palm oil used for this work contains sufficient nontriglyceride impurities to exhibit the apparent film boiling observed.

The canola oil used for this work exhibited minimal film boiling behavior compared to palm oil; this suggests that it would provide more uniform cooling. Additionally, increasing film boiling behavior may indicate increasing potential for distortion and cracking during increasing nonuniformity of surface thermal gradients [31,32].

\section{Conclusions}

The results of this study show that MATLAB can be used as a reliable tool for computing HTCs for different quenchants from their centerline time-temperature (cooling curve) data. Once the main scripts are established, optimization to match the thermal-physical nature of quenchant and probe can proceed quickly.

These calculations primarily involved solving systems of equations by using sufficiently small time steps through the cooling process. Furthermore, it was necessary that the probe size be much smaller than the volume of the quenchant. If these conditions do not effectively represent the true quench conditions, then it would be necessary to adjust the heat transfer computation equations to account for larger probe sizes of probes whose TCs are not aligned with the centerline of the probe. This assertion would be in line with the role of the Biot number, which scales directly with the product of HTC and the characteristic dimension of the probe and inversely with the thermal conductivity of the probe material.

The HTC data obtained from these calculations do provide a relatively quick and effective comparison of vitally important behaviors of a quenching medium.

It is important to note that although multiple TC probe data were used because of their availability, it was NOT our objective to utilize the surface TC data in this project. Instead, the objective was to develop a computational process that could be used for the current single TC INCONEL 600 cylindrical probe (12.5- $\mathrm{mm}$ diameter by $60 \mathrm{~mm}$ ) currently specified for use in ASTM standards: ASTM D6200 [14], ASTM D6482 [15], and ASTM D6549 [16]. However, the Tensi probe was initially developed by Tensi to model surface cooling mechanisms and their effect on quench uniformity; a future project to develop a simulation algorithm for checking the temperature differences between each TC placement of this probe during the cooling process would undoubtedly be interesting [31,32].

It is also important that one should not rely on the use of selected HTCs alone to evaluate quenching performance. This work has shown that the comparative inspection of the overall cooling profiles (cooling curves) is also important. For example, it was shown that canola oil, in view of its minimal film boiling behavior, would be expected to provide the most uniform interfacial cooling behavior. The pronounced film boiling behavior of palm oil was unexpected for the palm oil that was used in the as-purchased condition for this work. Furthermore, the cooling behavior of the palm oil used suggests that it is either poorly refined or contaminated.

It should be noted that the use of HTCs calculated from centerline TC data is limited to the use of relatively small probes, less than or equal to approximately $15 \mathrm{~mm}$ because of the errors typically involved. Therefore, application of the code developed here is limited to small diameter probes such as the 12.5-mm-diameter INCONEL 600 probe utilized for 
ASTM D6200, ASTM D6482, and ASTM D6549. Calculations of HTCs for probe diameters larger than approximately $12.5-15 \mathrm{~mm}$ typically require the use of at least a surface TC and often other TCs placed at different mid-radius positions in order to obtain optimal precision and accuracy as discussed in Refs. [17,18].

Finally, to facilitate the application of the lumped-parameter computational approach reported here, the MATLAB computation code is shown in the Appendix.

\section{Further Work}

This work is part of an ongoing research project to utilize the computational features of MATLAB for analysis of various heat treating problems such as quenching performance.

(1) The data used for this work were obtained using the Tensi multiple TC probe shown in Fig. 1. Although similar to the probe described in ASTM D6200 that utilizes a single TC inserted to the geometric center of a 12.5 - $\mathrm{mm}$-diameter by 60 -mm-long solid INCONEL 600 cylinder, the Tensi multiple TC probe is nominally different than the Tensi multiple TC probe based on a $15-\mathrm{mm}$-diameter by 45-mm-diameter INCONEL cylinder. Data from this probe were used simply because they were available. The final objective is to modify the computational code described in this article for routine use with the ASTM D6200 probe, which will have much greater applicability to the industry.

(2) A simulation algorithm for checking the temperature differences between each TC placement of the multiple TC Tensi probe during the cooling process would undoubtedly be an interesting method for quantifying and visualizing surface cooling gradients and quenching nonuniformity.

\section{ACKNOWLEDGMENTS}

The authors acknowledge their appreciation to CAPES (Coordenação de Aperfeiçoamento de Pessoal de Nível Superior) and Universidade de São Paulo (USP) for the financial support of this work.

\section{Appendix A: Reading EXCEL Files from MATLAB}

Sample MATLAB scripts shown here were developed and used for the 2016 version of EXCEL; hence, the file extension is of the form. xlsx. The same script can be read by MATLAB for earlier versions of EXCEL; one simply needs to modify the file extensions to the appropriate ones, for instance. xls.

Reading a simple EXCEL data file with one sheet is relatively straightforward. The syntax is shown as follows:

$\mathrm{D}=$ xlsread('SampleData.xlsx');

Reading larger EXCEL files with more than one data sheet requires adding an extra field in the data read statement as shown by the following:

The following MATLAB script was used for reading a large EXCEL data file with two embedded sheets, namely canola oil and palm oil. This specific session involved extracting temperature-time data for center TCs for two vegetable oil quenchants, canola oil and palm oil, respectively. 
The script has the flexibility to read different vector lengths of data, as shown in the cooling rate trends for the two oils. The time range is different, but this does not cause issues with MATLAB as long as the length of the corresponding temperature data matches the length of the time data.

\%Read the data from RS EXCEL data files

\%Create vectore corresponding to quenchants, then generate cooling curves mat $1=x l$ sread ('SampleData', 'Canola oil') ;

mat2 $=x l$ sread ('SampleData,' Palm oil') ;

t11 =mat $1(:, 1)$; \%time column for Canola oil

$\mathrm{T} 12=\operatorname{mat} 1(:, 2) \div$ Temp of center probe Canola oil

t21 = mat $2(:, 1) ; \%$ ime column for palm oil

T22 = mat $2(:, 2)$; $\frac{0}{T}$ Temp of center probe palm oil

$\%$

plot (t11, T12,'k.')

hold on

plot ( $221, \mathrm{~T} 22, \mathrm{\prime}^{\prime} \mathrm{k}^{\prime}$ )

legend('Canola oil center', 'palm oil center')

xlabel ('time in $\mathrm{s}$ ')

ylabel ('Temperature $\operatorname{deg} \mathrm{C}^{\prime}$ )

grid

A more practical script for handling four different sheets corresponding to the four quenchants covered in this study was derived by extending the script shown previously to generate cooling curves shown in Fig. 2.

\section{Appendix B: Heat Transfer Computation Code}

For brevity, part of the script for computing the HTCs for canola as a function of temperature is shown as follows.

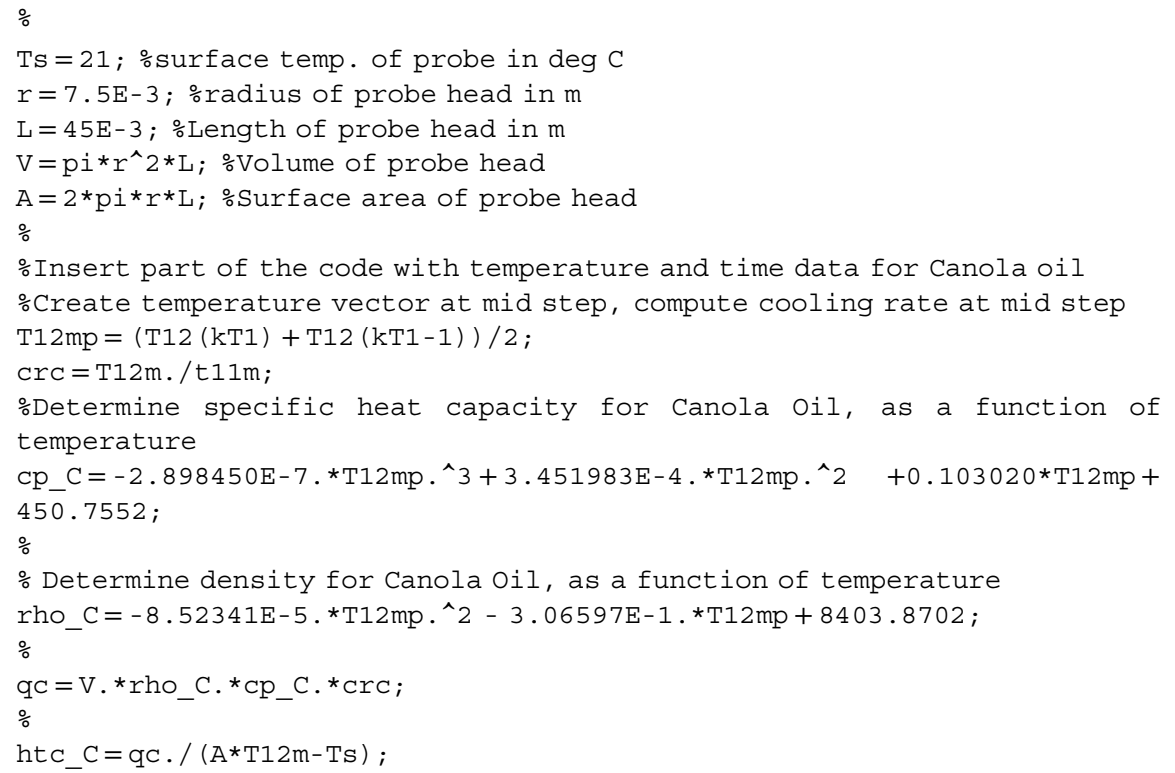




\section{Appendix C: Tabulated HTC versus Temperature Data}

For cases requiring look-up tables of computed HTCs as function temperatures for a quenchant of interest, the following snippet of code was used for generating the table for canola oil. For brevity, only a subset of the data in the neighborhood of maximum computed HTCs was used (See Fig. 4). Otherwise, the data can be as long as the sampling rate of the original temperature versus time data. The variable $\mathrm{cl}$ corresponds to the length of the variables of temperature and corresponding HTC values.



\section{References}

[1] Simencio Otero, R. L., Canale, L. C. F., and Totten, G. E., "Use of Vegetable Oils and Animal Oils as Steel Quenchants: A Historical Review-1850-2010," J. ASTM Int., Vol. 9, No. 1, 2012, pp. 1-38, https://doi.org/10.1520/JAI103534

[2] Eamon, W., Science and Secrets of Nature - Book of Secrets in Medieval Europe and Early Modern Culture, Princeton University Press, Princeton, NJ, 1994, pp. 86-87.

[3] MacKenzie, D. S. and Graham, G., "Beer, Blood, and Urine-Mythological Quenchants of Ancient Blacksmiths," presented at the 23rd IFHTSE Congress (IFHT 2016), Savannah, GA, April 18-21, 2016, ASM International, Materials Park, OH, pp. 101-109.

[4] Tagaya, M. and Tamura, I., "No. 123 - Studies on the Quenching Media: 3rd Report. The Cooling Ability of Oils," Technol. Rep. Osaka Univ., Vol. 4, 1954, pp. 305-319.

[5] de Souza, E. C., Fernandes, M. R., Augustinho, S. C. M., Canale, L. C. F., and Totten, G. E., "Comparison of Structure and Quenching Performance of Vegetable Oils," J. ASTM Int., Vol. 6, No. 9, 2009, pp. 1-25, https://doi.org/10.1520/JAI102188

[6] Carvalho de Souza, E., Belinato, G., Simencio Otero, R. L., Cícero Adão Simêncio, É., Augustinho, S. C. M., Capelupi, W., Conconi, C., Canale, L. C. F., and Totten, G. E., "Thermal Oxidative Stability of Vegetable Oils as Metal Heat Treatment Quenchants," J. ASTM Int., Vol. 9, No. 1, 2012, pp. 1-30, https://doi.org/10.1520/ JAI103817

[7] Belinato, G., Canale, L. C. F., and Totten, G. E., "Effect of Antioxidants on Oxidative Stability and Quenching Performance of Soybean Oil and Palm Oil Quenchants," J. ASTM Int., Vol. 8, No. 9, 2011, pp. 1-14, https://doi.org/10.1520/JAI103376

[8] Simencio Otero, R. L., Canale, L. C. F., Schicchi, D. S., Agaliotis, E., Totten, G. E., and Sarmiento, G. S., "Epoxidized Soybean Oil: Evaluation of Oxidative Stabilization and Metal Quenching/Heat Transfer Performance," J. Mater. Eng. Perform., Vol. 22, No. 7, pp. 1937-1944, https://doi.org/10.1007/s11665-013-0546-7

[9] Kobasko, N. I., Batista, A. A., Canale, L. C. F., Totten, G. E., and Dobryvechir, V. V., "Cooling Capacity of Coconut Oil, Palm Oil, and a Commercial Petroleum Oil by Solving the Heat Conductivity Inverse Problem," Mater. Perform. Charact., Vol. 2, No. 1, 2013, pp. 319-338, https://doi.org/10.1520/MPC20120047

[10] Simencio Otero, R. L., "Calculation of Kobasko's Simplified Heat Transfer Coefficients from Cooling Curve Data Obtained with Small Probes," J. ASTM Int., Vol. 9, No. 4, 2012, pp. 1-8, https://doi.org/10.1520/JAI104304 
[11] de Souza, E. C., Canale, L. C. F., Sarmiento, G. S., Agaliotis, E., Carrara, J. C., Schicchi, D. S., and Totten, G. E., "Heat Transfer Properties of a Series of Oxidized and Unoxidized Vegetable Oils in Comparison with Petroleum Oil-Based Quenchants," J. Mater. Eng. Perform., Vol. 22, No. 7, 2013, pp. 1871-1878, https://doi.org/10.1007/ s11665-013-0514-2

[12] Jagannath, V. and Prabhu, K. N., "Severity of Quenching and Kinetics of Wetting of Nanofluids and Vegetable Oils," J. ASTM Int., Vol. 6, No. 3, 2009, pp. 1-9, https://doi. org/10.1520/JAI101800

[13] Ramesh, G. and Narayan Prabhu, K., "Wetting and Cooling Performance of Vegetable Oils during Quench Hardening," Heat Transfer Asian Res., Vol. 45, No. 4, 2016, pp. 342-357, https://doi.org/10.1002/htj.21165

[14] ASTM D6200-01(2017), Standard Test Method for Determination of Cooling Characteristics of Quench Oils by Cooling Curve Analysis, ASTM International, West Conshohocken, PA, 2017, www.astm.org

[15] ASTM D6482-06(2016), Standard Test Method for Determination of Cooling Characteristics of Aqueous Polymer Quenchants by Cooling Curve Analysis with Agitation (Tensi Method), ASTM International, West Conshohocken, PA, 2016, www.astm.org

[16] ASTM D6549-06(2015), Standard Test Method for Determination of Cooling Characteristics of Quenchants by Cooling Curve Analysis with Agitation (Drayton Unit), ASTM International, West Conshohocken, PA, 2015, www.astm.org

[17] Liščić, B., "Measurement and Recording of Quenching Intensity in Workshop Conditions Based on Temperature Gradients," Mater. Perform. Charact., Vol. 5, No. 1, 2016, pp. 209-226, https://doi.org/10.1520/MPC20160007

[18] Matijevic, B., Liscic, B., Totten, G. E., and Canale, L. C. F., "Comparative Measurement and Evaluation of the Quenching Intensity of Palm Oil, Canola Oil and a Conventional Petroleum Oil Quenchant Based on Temperature Gradient Measurements," Mater. Perform. Charact., Vol. 6, No. 5, 2017, pp. 757-776, https:// doi.org/10.1520/MPC20170041

[19] Recktenwald, G., Numerical Methods with MATLAB: Implementations and Applications, 2nd ed., Prentice Hall, Upper Saddle River, NJ, 2000, 816p.

[20] Magrab, E. B., Azarm, S., Balachandran, B., Duncan, J. H., Herold, K. E., and Walsh, G. C., An Engineer's Guide to MATLAB, with Applications from Mechanical, Aerospace, Electrical, Civil, and Biological Systems Engineering, 3rd ed., Prentice Hall, Upper Saddle River, NJ, 2011, 848p.

[21] Ackerman, S. A., "AOS 340 - Physics of the Atmosphere and Ocean: II. What is MATLAB?” UW-MSN Space Science and Engineering Center, https://web.archive. org/web/20180917214111/http://cimss.ssec.wisc.edu/wxwise/class/aos340/spr00/ whatismatlab.htm (accessed 30 Aug. 2018).

[22] MathWorks, "MATLAB for Deep Learning," The MathWorks, Inc., https://web. archive.org/web/20180917220705/https://www.mathworks.com/ (accessed 17 Sep. 2018).

[23] Narazaki, M., Kogawara, M., Shirayori, A., and Fuchizawa, S., "Accuracy of Evaluation Methods for Heat Transfer Coefficients in Quenching," presented at the 18th ASM Heat Treating Society Conference Including the Liu Dai Symposium, Chicago, IL, Oct. 12-15, 1998, ASM International, Materials Park, OH, pp. 509-517.

[24] Funatani, K., Narazaki, M., and Tanaka, M., "Comparisons of Probe Design and Cooling Curve Analysis Methods," presented at the 19th ASM Heat Treating Society Conference Including Steel Heat Treating in the New Millennium, Cincinnati, OH, Nov. 1-4, 1999, ASM International, Materials Park, OH, pp. 255-263.

[25] Hosaeus, H., Seifter, A., Kaschnitz, E., and Pottlacher, G., "Thermophyical Properties of Solid and Liquid Inconel 718 Alloy," High Temp. High Pressures, Vol. 33, No. 4, 2001, pp. 405-410, https://doi.org/10.1068/htwu340

[26] de Souza, E. C., Canale, L. C. F., Sarmiento, G. S., Agaliotis, E., Carrara, J. C., Schicchi, D. S., and Totten, G. E., "Heat Transfer Properties of a Series of Oxidized and Unoxidized Vegetable Oils in Comparison with Petroleum Oil-Based Quenchants," 
presented at the 26th ASM Heat Treating Society Conference, Cincinnati, OH, Oct. 31-Nov. 2, 2011, ASM International, Materials Park, OH, pp. 235-243.

[27] Wolke, R. W., "Up in Smoke," Washington Post https://web.archive.org/web/ 20180917214607/http://www.washingtonpost.com/wp-srv/WPcap/1999-12/15/070r121599-idx.html?noredirect=on (accessed 30 Aug. 2018).

[28] Gee, P. T., "Analytical Characteristics of Crude and Refined Palm Oil and Fractions," Eur. J. Lipid Sci. Technol., Vol. 109, No. 4, 2007, pp. 373-379, https://doi.org/10.1002/ ejlt.200600264

[29] Retief, L., "Analysis of Vegetable Oils, Seeds and Beans by TGA and NMR Spectroscopy," Ph.D. thesis, University of Stellenbosch, Stellenbosch, South Africa, 2011.

[30] Aluyor, E. O., Ozigagu, C. E., Oboh, O. I., and Aluyor, P., "Chromatographic Analysis of Vegetable Oils: A Review,” Sci. Res. Essay, Vol. 4, No. 4, 2009, pp. 191-197.

[31] Tensi, H. M., Stich, A., Spies, H. J., and Spengler, A., "Grundlagen des Abschreckens durch Tauchkühlen (Principles of Quenching by Immersion)," HTM Härterei Tech. Mitt., Vol. 50, No. 4, 1995, pp. 254-258.

[32] Tensi, H. M., Stich, A., and Totten, G. E., "Fundamentals of Quenching," Metal Heat Treat., March/April, 1995, pp. 20-28. 